much favour by the public, that it shows there is a great want for some rapid means of getting a limited number of copies of letters, \&c. ; and seeing that any number of colours may be used in the original drawing, Mr. Norman Lockyer has suggested that it would be of much use in laboratories, for the multiplication of original sketches of biological specimens, and even for spectra charts, and so save much of the time spent in making duplicate copies. The gelatin slab cannot be said to be perfect, as it is liable to be affected by atmospheric changes; but, bearing in mind the fact that the whole is simply a sponge filled with a compound capable of liquefying certain inks, it is reasonable to hope and expect that chromography is only the pioneer of a process, which shall possess all its advantages and none of its defects.

R. H. RIDOUT

\section{THE ANIMAL HEAT OF FISHES}

$T^{H E}$ $\mathrm{E}$ belief that fishes are cold-blooded, that is, that they take on the temperature of the water which surrounds them, with no power to resist it, and that they develop little or no animal heat themselves, is still held by many even scientific observers, This belief is based partly upon the well-authenticated fact that fishes have been frozen and thawed again into life; partly upon the statements of many travellers who have found them living in water of a very high temperature (Humboldt and Bonpland recording the highest, $210^{\circ} \mathrm{F}$.); and further, that a thermometer inserted into the rectum of some living fish freshly drawn from the water has been repeatedly found to indicate temperature corresponding very closely to that of the water itself.

During the past summer, and in connection with the operations of the U.S. Fish Commission at Provincetown, Mass., Surgeon J. H. Kidder, of the U.S. Navy, was detailed to make some systematic observations upon the subject of fish-temperatures with a view to setting the question upon a secure basis of actual experiment. Thermometers were made expressly for the purpose by Mr. John Taglialne, of New York, of unusual delicacy, registering about $10^{\circ} \mathrm{F}$. each, and recording fifths of a degree. These were used in connection with Negretti and Zambra's deep-sea thermometers, and all the instruments were deduced to a single standard by frequent comparisons, so as to insure relative accuracy. The fish were taken with a line, and their temperatures observed at once, care being taken that no considerable change in temperature occurred during the time consumed in bringing the fish to the surface. The observed temperatures were then compared with that of the water as recorded by a Negretti-Zambra thermometer sunk to about the depth from which the fishes were taken. The first observations, made by inserting the thermometer into the rectum of the fish, agreed with the generally-received opinion, showing but little higher temperature than that of the surrounding water.

The mode of experiment was then somewhat modified. Considering the fact that the intestinal canal of a fish is in close contact with the thin and scarcely vascular walls of the abdomen, which is surrounded by the water in which the animal swims; and, further, that the arterial blood comes from the gills, where it has been spread out as thinly as possible and brought into the closest contact with the surrounding water-a process well calculated to cool it quickly to the same temperature-it follows that neither the interior of the rectum nor the arterial blood would appear to have the same value as representing the body-temperature in fishes that those parts possess in mammals and birds. It is rather in the venous circulation and the branchial artery that we should seek for the heat which must certainly be developed in the chemical processes of nutrition and waste, and in connection with active muscular movements. In the remaining experiments of the series-about ninety in number-the fish was therefore opened at once, and the bulb of the thermometer inserted into the cavity of the heart, or branchial artery, with the results indicated in the following table, which shows the averages :-

\begin{tabular}{|c|c|c|c|c|}
\hline Fish. & $\begin{array}{l}\text { Temp. of } \\
\text { surround- } \\
\text { ing water. }\end{array}$ & Rectum. & $\begin{array}{l}\text { Venous } \\
\text { blood. }\end{array}$ & Remarks. \\
\hline 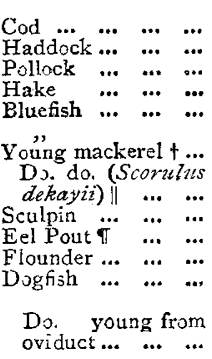 & 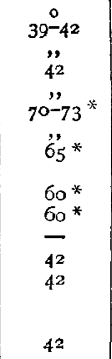 & $\begin{array}{r}0 \\
+0.98 \\
+1.30 \\
+2.40 \\
+2.40 \\
+0.25 \\
+0.50 \\
+4.10 \\
+\overline{0} \\
+30 \\
+3.00 \\
+4.40\end{array}$ & 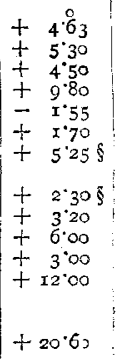 & $\begin{array}{l}\text { Oriducts contained } \\
\text { mature young. }\end{array}$ \\
\hline
\end{tabular}

It appears from these experiments that fishes do develop a measurable quantity of animal heat, which is more apparent during the spawning season, and much greater in elasmobranchs (as is to be expected from their more perfect digestive and assimilative apparatus) than in other fishes. It also appears that the measure of this animal heat is to be sought in the venous blood, and not in the intestinal canal or arterial blood.

The limits of this preliminary note will not permit us to go into an enumeration of the difficulties of observation or the measures taken to guard against the errors likely to attend them. Nor is the number of observations (ninety-five in all) sufficient to warrant the offering of these figures as a final statement of the degree of animal heat presented by the several fishes observed. All that can be said to be proved so far is the fact that fishes do manifest animal heat, and in considerable quantities, sufficient to warm again, to the extent of from $3^{\circ}$ to $12^{\circ}$, blood that has been cooled in each circuit to the temperature of the surrounding water. Details will be given in the forthcoming report of the United States Fish Commission.

In the single instance of a lower temperature than that of the water, observed in five blue-fish, all taken on the same day, it may be that the individuals experimented on, being taken at the surface, had just come up from a much greater depth and colder stratum of water. There seems to be no conceivable provision by which a fish can maintain a temperature below that of the surrounding water, cooling by evaporation being out of the question. The young dogfish from its mother's oviduct showed a temperature $8^{\circ}$ higher than that of the mother herself, for the obvious reason that its blood, not coming into contact with the water by its gills (the umbilical sac was still attached), was not cooled otherwise than mediately, through the blood of the mother.

\section{NEW MODES OF SHOWING DIFFERENT CHARACTERISTICS OVER SMALL ARCS IN AZIMUTH FROM THE SAME LIGHT- HOUSE APPARATUS}

WHERE a light on a rock or island has to illuminate constantly the whole horizon, the ordinary dioptric fixed apparatus is all that is required. But when, as at

*Surface-swimmers † "Sinkers." $\ddagger$ Stomach, through œsophagus. $\$$ Temperature taken in blood flowing from heart, the crgan being too small to admit the thermometer.

II This rare species, not seen in Massachusetts Bay for thirty years, appeared, young, at Provincetown last summer in considerable numbers.

If Zoarces angzilllaris.
The sign "+ "indicates excess, and " - " deficiency, as compared with temperature of water. 
many places, there is a shoal at some distance from the lighthouse, or where a reef of rocks projects seawards from the shore, it sometimes becomes necessary to adopt means for keeping ressels clear of such dangers at night, as, for example, near Souter Point, where Mr. Douglass and Mr. J. T. Chance employed successfully the electric light for guarding a rock near the shore. What is wanted in such cases is to cover not only the danger itself but some area of the surrounding sea by a characteristic which is different from that of the main light.

If in front of a fixed light apparatus whose optical property is to parallelise the rays in the vertical plane while not interfering with their natural divergence in azimuth, there be placed an arrangement of straight horizontal shades or screens similar to the Venetian blinds which are used for house windows, the means will be supplied for easily producing different distinctions. The breadth of those blinds must be such as to subtend from the central flame the same angle as that over which the necessary distinction has to be shown at sea. By opening and shutting simultaneously and gradually the different leaves of the blind, there will be produced the same characteristics as those of an ordinary revolving or flashing light, according as the leaves are moved slowly or quickly and kept shut for a certain period, and these distinctions will be accompanied by the necessary gradual waxing and waning of the emergent rays. By simultaneously opening and shutting the leaves of the blind suddenly, and keeping them open so as to show a fixed light for a certain length of time, and then keeping them shut so as to produce darkness for a certain length of time, the effect of an intermittent light in which there is no waxing or waning of the rays will obviously be produced.

Should it be considered desirable to vary the appearance over the giren arc so as to show a gradually increasing length of light period when a vessel is approaching the danger, the maximum period when it is opposite to it, and a correspondingly shortening period as the vessel leaves it, a single straight opaque mask placed outside of the apparatus, and revolving horizontally and with uniform speed on a vertical spindle will produce the result. For while the periods of change will remain the same over the whole arc the duration of darkness will gradually increase as the danger is approached, and gradually decrease after the danger has been passed. And if this vertical shade be made to rotate at a slow and uniform speed it will produce the effect of a revolving light, and if at a quick speed it will produce the effect of a flashing light, with this difference that the flashes will recur ivith only an instantaneous interval of darkness, and in both cases there will be a gradual waxing and waning of the rays.

By these very simple and cheap expedients a fixed light illuminating the whole horizon (by means of a flame of he ordinary size in relation to the focal length) can easily be made to show accurately over any limited angle in azimuth the effects of the different distinctions referred to, and these combinations will therefore supply a deside. ratum which is often much wanted in coast illumination. In some experiments which were made all these characteristics were successfully produced by the two modes described.

Where no light is required in any part of the horizon but in one small arc only, as, for example, in illuminating the middle of a long narrow Sound, all the rays proceeding from the lamp should be spread equally over that arc. A fixed holophote with an opaque disk revolving horizontally in front on a vertical spindle will, if condensing prisms are placed between the disk and the holophote, produce either a revolving or flashing light according to the speed of its revolution, but without any intervening period of darkness. If colour distinction be required and a revolving disk of glass be substituted for the opaque mask the characteristic effect produced would be that of a revolving red and white light without any intervening dark period between the flashes, which would gradually dissolve into each other from red to white and then from white to red. Edinburgh, October 22 THOMAS STEVENSON

\section{A FEAT IN TRIANGULATION}

A NOTEWORTHY advance in geodesy has recently been accomplished by the junction of the network of measurements covering a large portion of the surface of Europe, with the African continent. The entire triangulation of Algeria was completed by French engineers some time since, and extended to the edge of the Sahara, in lat. $37^{\circ}$. M. Perrier, who had directed in a great measure the triangulation of Algeria, bas for the past eleven years been seeking the means of joining the network in that country with the perfect trigonometric system covering the surface of Spain, France, and England. The importance of such a junction is easily appreciated when we consider what notable changes in the accurate conception of the shape of the earth and of the length of meridians has been effected by measurements on a much smaller scale.

For such an undertaking the most careful and painstaking preparations were requisite. As the result of his reconnaissances between 1868 and 1872 , M. Perrier found that from ail the trigonometric points of the first order between Oran and the frontiers of Morocco, the loftier crests of the Sierra Nevada on the Spanish coast opposite, were visible in exceptionally clear weather. Arrangements were subsequently made with the Spanish Geographical Institute for the mutual and contemporaneous execution. of the proposed plan. A corps of Spanish officers, under the direction of the well-known General Ibanez, was detailed for this purpose, while the French Minister of War placed a division of officers from the Etat-Major under the command of $M$, Perrier. The leaders chose for stations in Algeria the summits of Mount Filhaoursen and Mount M'Sabiha, west of Oran, and in Spain the summits of Mount Tetica and Mount Mulhacen, the latter of which is the most elevated point in the kingdom. The directions and distances between these four points were computed as carefully as possible, and preparations were then made for the final and determinative observations. At the Algerian stations the nature of the country and its inhabitants necessitated the use of a numerous force of soldiery as well as of means of transport.

In order to insure the accuracy of the observations, which required the passage of signals over a distance of 270 kilometres, it was decided to make use of solar reflectors and powerful lenses. The efficacy of such apparatus for even greater distances had already been tested by M. Perrier; still for the measurements in question they appear to have utterly failed to answer the expectations based upon them, not a single solar signal being visible from any station. Fortunately, the success of the observations did not rest entirely upon this one system of signals. Preparations had likewise been made for the employment of the electric light, and on the summit of each mountain one of Gramme's electro-magnetic machines worked by engines of 6-horse power had been placed in position.

On August 20 last, all the stations were occupied, and the electric lights were displayed throughout each night. Then the patience of the observers was submitted to a lengthy proof. The mists rising from the Mediterranean totally prevented the exchange of signals, until after a delay of twenty days, one after another the electric lights became visible even to the naked eye. Perrier compared the intensity of the light on Tetica nearly 270 kilometres distant, to that of $a$ in Ursa Major, which rose near by. The observations were continued from September 9 to October I8, when this task for which such extensive preparations had been made, was completed in the most satisfactory manner. With its completion we come into 